\title{
Effect of the Fluidity on the Ionic Tracer Diffusion of Thallium(I) Ion in Aqueous Solutions Containing Hydrophilic Polymers
}

\author{
Katsuo TAKAHASHI*, Kazuo TSUGAWA**, Yoko MATSUOKA**, Toshiaki IsONO* and \\ Reita TAMAMUSHI*
}

\begin{abstract}
Diffusion coefficients, $L$, of thallium( $($ ) ion in aqueous solutions containing poly (ethylene oxide) and poly (vinyl alcohol) (abbreviated as PEO and PVA, respectively) were measured by potential-step chronoamperometry, normal pulse-polarography, and dc-polarography. When the polymer concentration was varied at constant temperature, the effect of fluidity, $\phi$, of the solution on the diffusion coefficient was found to obey the empirical equation, $D \phi^{q}=$ const, where $0<q \leq 1$. In solutions containing $\mathrm{PEO}$ of lower molecular masses, $q$ was very close to unity; in the other solutions, however, $q$ decreased remarkably with increasing molecular mass of the polymer, indicating that the effect of polymer on the viscous flow is greater than that on the mobility of $T l(I)$ ions in solution. Such a difference between the effects of polymers on the fluidity and diffusion can be attributed to the loose network structure of polymers in the solution.
\end{abstract}

\section{Introduction}

The mobility of ions in solution is correlated to the ion size and the viscosity of the solution by the well-known Stokes law which is based on the model of the movement of a spherical particle in a viscous medium. Classical theories suggest that the diffusion coefficient of ions in solution is directly proportional to the fluidity of the solution (Walden's rule) ${ }^{1 \sim 3}$. In solutions containing polymers or colloids, however, significant deviations from Walden's rule have been reported by many workers. The obstruction effect of polymers, the difference between macroscopic and microscopic viscosities, polymer-ion interactions, and the effect of polymers on the water structure are considered to be important factors affecting the correlation between the fluidity and ionic mobility ${ }^{411}$.

In this work, the effect of fluidity on the diffusion coefficient of small ions was investigated in aqueous solutions containing hydrophilic polymers of different molecular masses and different concentrations. Poly (ethylene oxide) and poly (vinyl alcohol) were chosen as water-soluble polymers because of the following reasons: (1)

* The Institute of Physical and Cremical Research (Hirosawa, Wako-shi, Saitama)

** Faculty of Science, Gakushuin University (Mejiro, Toshimaku, Tokyo)

Key Words: Diffusion Coefficient, Fluidity, Thallium (1) Ion, Poly (ethylene oxide), Poly (vinyl alcohol), Walden's Rule pure samples of various molecular masses are available on the market, (2) aqueous solutions of wide range of fluidity can be prepared, and (3) they are materials of practical importance. The diffusion coefficient was measured by potential-step chronoamperometry (PSCA), normal pulse-polarography (NPP), and dc-polarography (DCP). Among these electrochemical methods, PSCA and NPP provide reasonably accurate values of ionic tracer diffusion coefficients which are important quantities in the electrochemistry of ions. $\mathrm{Tl}(\mathrm{I})$ ion was chosen as the diffusing species; this is because that the polarographic reduction of $\mathrm{Tl}(\mathrm{I})$ gives a well-defined, diffusion-controlled wave and practically no interactions of $\mathrm{Tl}(\mathrm{I})$ with the polymer and supporting electrolyte are expected. In contrast to $\mathrm{Tl}(\mathrm{I}), \mathrm{Cd}(\mathrm{II})$ and $\mathrm{Pb}$ (II) ions showed complicated reduction waves on $\mathrm{dc}$ and square-wave polarograms in aqueous solutions containing PEO and were not used in the present study.

\subsection{Materials}

\section{Experimental}

Poly(ethylene oxide)s used were Polyethylene Glycols (PEG 200, 600, 1540, 4000, 6000 and 20000) as supplied by Wako Pure Chemical Industries Ltd, and PEO 3 and PEO 18 as supplied by Seitetsu Kagaku Co., Ltd. Polyvinyl Alcohols (PVA 500, 800 and 2000) were supplied by Wako Pure Chemical Industries Ltd. 
In this paper we use common symbol PEO for Polyethylene Glycols and PEO's, and PVA for Polyvinyl Alcohols.

Sodium perchlorate and thallium (I) nitrate were special reagent chemicals and used without further purification.

All solutions containing the polymer and supporting electrolyte were prepared gravimetrically by using redistilled water; the composition of a polymer-water mixture is given in terms of the mass-fraction of the polymer, $f_{m}$. The concentration of $\mathrm{NaClO}_{4}$ was $0.5 \mathrm{~mol}$ in $1 \mathrm{~kg}$ of a polymer-water mixture.

In electrochemical measurements, a sample solution containing $1 \sim 2 \mathrm{mM} \mathrm{Tl}(\mathrm{I})$ was prepared by adding an appropriate volume of $\mathrm{TiNO}_{3}$ $(0.1 \sim 0.3 \mathrm{M})$ stock-solution to $50 \mathrm{~cm}^{3}$ of the polymer-water mixture in the polarographic cell by means of a micro-sylinge. Prior to each measurement, all sample solutions were deaerated by bubbling oxygen-free nitrogen gas for $15 \sim$ 40 minutes.

\subsection{Diffusion coefficient and fluidity measurements}

The electrochemical measurements were carried out by using the following instruments: Potentiostat Model 361 and Polarograph Medel 312 (Fuso Seisakusho), Trangent Time Converter TCA 2000 (Riken Denshi Co., Ltd.), and X-Y Pen-Recorder WX 451 (Watanabesokki).

The polarographic cell used was of a conventional three-electrode type. The counter electrode was a bright $\mathrm{Pt}$-spiral and the reference electrode was a saturated calomel electrode (SCE) with $0.5 \mathrm{M} \mathrm{NaNO}_{3}$ aq. salt bridge. The working electrodes were dropping mercury electrodes (DME) of conventional design. The drop time of DME was electro-mechanically controlled at $4.0 \mathrm{~s}$ or $6.0 \mathrm{~s}$. The flow rate of mercury was determined to be $0.9 \sim 1.3 \mathrm{mg} \mathrm{s}^{-1}$ from the weight of mercury consumed in each polarographic measurement. Some measurements were also made at a hanging mercury drop electrode (HMDE), Model 9323 (Princeton Applied Research).

Cannon-Fenske and Ubbelohde viscometers and a falling-ball viscometer were used to measure the fluidity of the polymer-water mixtures containing the supporting electrolyte (without depolarizer). Further details of the experimental procedures for the fluidity and density measurements have been reported in separate papers ${ }^{12,16)}$.

All electrochemical measurements were carried out in a thermostated water-bath of $25.0 \pm 0.1^{\circ} \mathrm{C}$.

\section{Results and Discussion \\ 3.1 Electrochemical determination of dif- fusion coefficients}

The measurement of diffusion-controlled limiting currents in DCP is often used to determine the diffusion coefficients of depolarizers ${ }^{23,14}$. According to Ikeuchi et al., however, PSCA using a HMDE constructed with a specifically designed capillary provides the best method of determining the diffusion coefficient ${ }^{15}$. In this work, PSCA and NPP, both with a conventional DME, were used; the use of the conventional DME is preferable to the HMDE in highly viscous media, and gives diffusion coefficients with sufficiently high accuracy. Classical DCP was also employed for comparison.

The PSCA measurement was carried out under the following conditions. A potential-step from $-0.2 \mathrm{~V}$ to $-0.7 \mathrm{~V}$ (vs. SCE) was applied at $0.2 \mathrm{~s}$ before dislodging the DME whose droptime, $t_{\mathrm{d}}$, was $4 \mathrm{~s}$ or $6 \mathrm{~s}$, and the diffusion-controlled current $\left(I_{\mathrm{d}}\right)$-time $(t)$ curves were measured from the moment of the potential-step upto 100 ms. $I_{\mathrm{d}}$ was then plotted against $t^{-1 / 2}$ in the time region $20 \mathrm{~ms}<t<100 \mathrm{~ms}$. The $I_{\mathrm{d}}-t^{-1 / 2}$ plot showed good linearity and its slope gives the diffusion coefficient, $D$, based on Cottrel's equation (1) for the spherical diffusion;

$$
I_{\mathrm{d}}=F \operatorname{FncD}\left[(\boldsymbol{x} D t)^{-1 / 2}+r^{-1}\right]
$$

where $F$ is Faraday constant, $n$ the number of electrons concerned in the reaction, $c$ the bulk concentration of depolarizer, and $r$ and $S(=4$ $\left.\pi r^{2}\right)$ are the radius and surface area of the electrode, respectivery ${ }^{13)}$. In the present study the electrode reaction is the reduction of $\mathrm{Tl}(\mathrm{I})$ to $\mathrm{Tl}(\mathrm{Hg})$ with $n=1$.

In NPP, the current was sampled at a given time, $t(t=30,50$, and $70 \mathrm{~ms})$, and the diffusion coefficient was calculated by applying eq. (1) to the diffusion-controlled limiting current, $I_{\mathrm{d}}$, on normal-pulse polarograms. The working principle of determining diffusion coefficients in NPP is the same as that in PSCA, and the results obtained by these methods were in good 
agreement and will not be distinguished in this paper.

In the case of DCP, the original and modified Ilkovic equations, (2) and (3) respectively, were used for the calculation of diffusion coefficients from the diffusion controlled limiting current $^{13)}$;

$$
\begin{aligned}
& I_{\mathrm{d}}=F \operatorname{Snc}(7 D)^{1 / 2}\left(3 \cdots t_{\mathrm{d}}\right)^{-1 / 2} \\
& I_{\mathrm{d}}=F \operatorname{SncD}\left[r^{-1}+\left(3 \pi D t_{\mathrm{d}} / 7\right)^{-1 / 2}\right]
\end{aligned}
$$

Figure 1 shows the diffusion coefficients of $\mathrm{Tl}(\mathrm{I})$ in $\mathrm{PEG} 200-\mathrm{H}_{2} \mathrm{O}$ and PVA $500-\mathrm{H}_{2} \mathrm{O}$ mixtures obtained by the DCP and PSCA, where $D_{11 \mathrm{k}}, D_{1 \mathrm{k}}^{\prime}$ and $D_{\mathrm{PSCA}}$ are the diffusion coefficients determined by equations (2) and (3) for DCP, and (1) for PSCA, respectively. The ratio, $D_{\mathrm{Ilk}} / D_{\mathrm{PSCA}}$, is also included in the same figure. It can be seen from these results that the diffusion coefficients obtained by DCP and PSCA do not agree and the ratio, $D_{\mathrm{Ilk}} / D_{\mathrm{PSCA}}$, depends on the polymer concentration.

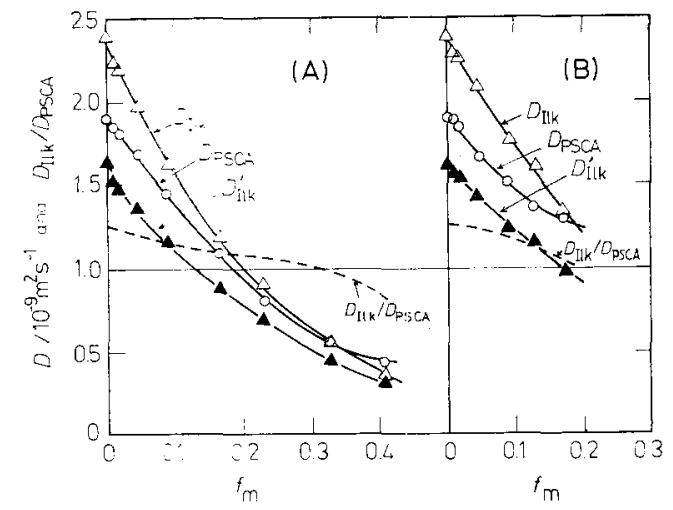

Fig. 1 Diffusion coefficierts of $\mathrm{Tl}(\mathrm{I})$ ion obtained by PSCA and DCP in solutions of PEG 200 (A) and PVA 22000 (B) at $25.0^{\circ} \mathrm{C}\left(f_{m}\right.$, mass fraction of polymers; supporting electrolyte, 0.5 mol $\mathrm{NaClO}_{4}$ in $1 \mathrm{~kg}$ of polymer- $\mathrm{H}_{2} \mathrm{O}$ mixture)

In order to examine the possibility if the difference between $D_{\mathrm{Ilk}}$ (or $D_{\mathrm{Ilk}}^{\prime}$ ) and $D_{\mathrm{PSCA}}$ could be due to the difference in the time domain of measuring currents in DCP and PSCA, the analysis of chronoamperometric current-time curves was made over a very wide time region, ranging from $3 \mathrm{~ms}$ to $10 \mathrm{~s}$. Figure 2 shows the values of $D_{\mathrm{PSCA}}$ of $\mathrm{Tl}(\mathrm{I})$ in aqueous solutions containing no polymers (A) and

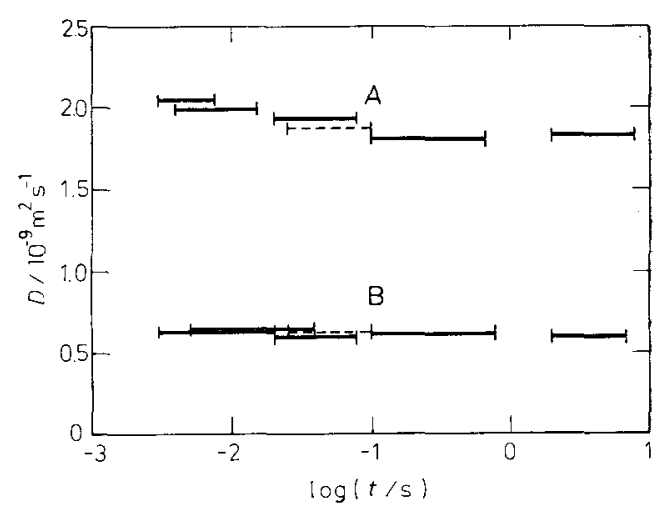

Fig. 2 Diffusion coefficients of $1 \mathrm{mM} \mathrm{Tl}$ ( I ) ion at $25^{\circ} \mathrm{C}$ obtained by PSCA as a function of time domain of current measurement (solid lines represent the values obtained at a HMDE and broken lines represent those values at a DME)
A : In aqueous solutions containing $\mathrm{NaClO}_{4}$ (molality $=0.5 \mathrm{~mol} / \mathrm{kg}$ )
B : In aqueous solutions containing $\mathrm{NaClO}_{4}$ (molality $=0.5 \mathrm{~mol} / \mathrm{kg}$ ) and PEG 20000 $\left(f_{m}=0.167\right)$

in solutions containing PEG 20000 (B) as a function of the time domain of current measurement. In both solutions, the $D$-values were found to be independent of the time of measurement, and no significant difference was observed between the $D$-values obtained with the DME and the HMDE. These results suggest that the diffusion process observed by PSCA does not change during the time region of $10^{-3}$ $-10 \mathrm{~s}$, although the diffusion layer thickness increases from $10^{-6}$ to $10^{-4} \mathrm{~m}$ with increasing time from $10^{-3}$ to $10 \mathrm{~s}$.

Considering the above-mentioned observation and that the model of the diffusion process in PSCA is simpler than in DCP, we can conclude that the diffusion coefficients obtained by PSCA are more reliable and accurate than those by DCP, and we employ the former values in the following discussion.

\subsection{Fluidities and densities of polymer- water mixtures and diffusion coef- ficients of $T(I)$ in the mixtures}

The fluidity, $\phi$, and density, $\rho$, of polymerwater mixtures of different compositions and the diffusion coefficient, $D$, of $\mathrm{Tl}(\mathrm{I})$ in the mix- 
Table 1 Density, $\rho$, and fluidity, $\phi$, of aqueous polymer solutions and diffusion coefficient, $D$, of $1 \mathrm{mM} \mathrm{Tl}(\mathrm{I})$ ion in the solution at $25^{\circ} \mathrm{C}$

\begin{tabular}{|c|c|c|c|c|c|c|}
\hline Polymers & $M_{\mathrm{r}}$ & $M_{\mathrm{r}}^{\prime}$ & $f_{m}$ & $\rho / \mathrm{g} \mathrm{cm}^{-3}$ & $\phi / \mathrm{Pa}^{-1} \mathrm{~s}^{-1}$ & $D / 10^{-9} \mathrm{~m}^{2} \mathrm{~s}^{-1}$ \\
\hline$\left(\mathrm{H}_{2} \mathrm{O}\right)$ & - & - & 0 & 1.0347 & 1106 & 1.86 \\
\hline \multirow[t]{8}{*}{ PEG 200} & \multirow[t]{8}{*}{200} & \multirow[t]{8}{*}{200} & 0.0099 & 1.0355 & 1074 & 1.86 \\
\hline & & & 0.0196 & 1.0375 & 1041 & 1.82 \\
\hline & & & 0.0476 & 1.0415 & 952 & 1.68 \\
\hline & & & 0.0909 & 1.0478 & 825 & 1.44 \\
\hline & & & 0.167 & 1.0589 & 632 & 1.09 \\
\hline & & & 0.231 & 1.0688 & 498 & 0.81 \\
\hline & & & 0.333 & 1.0846 & 329 & 0.56 \\
\hline & & & 0.412 & 1.0973 & 233 & 0.43 \\
\hline \multirow[t]{3}{*}{ PEG 600} & \multirow[t]{3}{*}{600} & \multirow[t]{3}{*}{590} & 0.0196 & 1.0376 & 1058 & 1.78 \\
\hline & & & 0.0909 & 1.0481 & 704 & 1.07 \\
\hline & & & 0.167 & 1.0607 & 499 & 0.76 \\
\hline \multirow[t]{3}{*}{ PEG 1540} & \multirow[t]{3}{*}{1540} & \multirow[t]{3}{*}{-} & 0.0196 & 1.0371 & 1016 & 1.74 \\
\hline & & & 0.0909 & 1.0473 & 575 & 1.06 \\
\hline & & & 0.167 & 1.0612 & 350 & 0.63 \\
\hline \multirow[t]{7}{*}{ PEG 4000} & \multirow[t]{7}{*}{3000} & \multirow[t]{7}{*}{3300} & 0.0099 & 1.0361 & 1000 & 1.87 \\
\hline & & & 0.0196 & 1.0378 & 904 & 1.80 \\
\hline & & & 0.0476 & 1.0423 & 682 & 1.45 \\
\hline & & & 0.0909 & 1.0489 & 448 & 1.08 \\
\hline & & & 0.167 & 1.0611 & 235 & 0.64 \\
\hline & & & 0.231 & 1.0719 & 128 & 0.49 \\
\hline & & & 0.333 & 1.0888 & 61 & 0.26 \\
\hline \multirow[t]{3}{*}{ PEG 6000} & \multirow[t]{3}{*}{7500} & \multirow[t]{3}{*}{5700} & 0.0196 & 1.0378 & 795 & 1.74 \\
\hline & & & 0.0909 & 1.0490 & 246 & 1.01 \\
\hline & & & 0.167 & 1.0614 & 83 & 0.63 \\
\hline \multirow[t]{7}{*}{ PEG 20000} & \multirow[t]{7}{*}{20000} & \multirow[t]{7}{*}{11700} & 0.0099 & 1.0368 & 714 & 1.76 \\
\hline & & & 0.0196 & 1.0375 & 488 & 1.62 \\
\hline & & & 0.0476 & 1.0421 & 199 & 1.33 \\
\hline & & & 0.0909 & 1.0496 & 62 & 0.93 \\
\hline & & & 0.130 & 1.0559 & 28 & 0.71 \\
\hline & & & 0.167 & 1.0613 & 13.6 & 0.57 \\
\hline & & & 0.231 & 1.0728 & 4.6 & 0.47 \\
\hline \multirow[t]{3}{*}{ PEO 3} & \multirow[t]{3}{*}{$\sim 5 \times 10^{5}$} & \multirow[t]{3}{*}{-} & 0.0196 & 1.0378 & $27 *$ & 1.6 \\
\hline & & & 0.0476 & 1.0422 & $0.83^{*}$ & 1.2 \\
\hline & & & 0.0909 & 1.0491 & $0.02^{*}$ & 0.8 \\
\hline \multirow[t]{3}{*}{ PEO 18} & \multirow[t]{3}{*}{$\sim 4 \times 10^{6}$} & \multirow[t]{3}{*}{-} & 0.0050 & - & $3^{*}$ & 1.7 \\
\hline & & & 0.0099 & - & $0.4^{*}$ & 1.5 \\
\hline & & & 0.0196 & - & $0.06^{*}$ & 0.9 \\
\hline \multirow[t]{3}{*}{ PVA 300} & 13000 & 2000 & 0.0196 & 1.0397 & 574 & 1.77 \\
\hline & & & 0.0476 & 1.0446 & 262 & 1.64 \\
\hline & & & 0.0909 & 1.0565 & 79 & 1.37 \\
\hline
\end{tabular}




\begin{tabular}{|c|c|c|c|c|c|c|c|}
\hline Polymers & $M_{\mathrm{r}}$ & $M_{\mathrm{r}}^{\prime}$ & $f_{m}$ & $\rho / \mathrm{g} \mathrm{cm}^{-3}$ & $\phi / \mathrm{Pa}^{-1} \mathrm{~s}^{-1}$ & : & $D / 10^{-9} \mathrm{~m}^{2} \mathrm{~s}^{-1}$ \\
\hline \multirow[t]{6}{*}{ PVA 500} & \multirow[t]{6}{*}{22000} & \multirow[t]{6}{*}{4000} & 0.0099 & 1.0375 & 769 & & 1.78 \\
\hline & & & 0.0196 & 1.0398 & 540 & & 1.74 \\
\hline & & & 0.0476 & 1.0450 & 201 & ! & 1.56 \\
\hline & & & 0.0909 & 1.0558 & 48 & & 1.44 \\
\hline & & & 0.130 & 1.0641 & 14.4 & 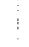 & 1.28 \\
\hline & & & 0.167 & 1.0748 & 5.3 & . & 1.24 \\
\hline \multirow[t]{2}{*}{ PVA 1500} & \multirow[t]{2}{*}{66000} & \multirow[t]{2}{*}{ - } & 0.0476 & 1.0466 & 38 & & 1.62 \\
\hline & & & 0.0909 & 1.0561 & 3.3 & & 1.51 \\
\hline
\end{tabular}

— : Not determined, $*$ : Non-Newtonian

tures are summarized in Table 1. In the second and third columns of the table, average relative molecular masses of polymers, $M_{\mathrm{r}}$ and $M_{\mathrm{r}}{ }^{\prime}$, are listed, where $M_{\mathrm{r}}$ is a nominal value indicated on the manufacturer's specifications and $M_{\mathbf{r}}{ }^{\prime}$ is that determined by a vapor-pressure osmometer (Hewlett Packard, Model 302). In the case of PEG 20000 and PVA, $M_{\mathrm{r}}$-values are significantly different from $M_{\mathrm{r}}^{\prime}$ by some unknown reasons; we shall not discuss this disagreement in this paper.

The half-wave potential of $\mathrm{Tl}(\mathrm{I})$ reduction was equal to $-0.474 \pm 0.002 \mathrm{~V}$ vs. SCE, independent of the mixture composition: this result indicates that practically no interaction is considered between $\mathrm{Tl}(\mathrm{I})$ and polymer molecules.

\subsection{Relationship between the fluidity and diffusion coefficient}

Stokes et al. have proposed that the ionic mobility at infinite dilution, $\lambda^{\infty}$, is correlated to the viscosity of solution, $\eta$, by an enpirical equation;

$\lambda^{\infty} \eta^{q}=\mathrm{constant}$

which may be called modified Walden's rule ${ }^{2, \bar{p}}$.

In the application of this empirical equation, it is important to distinguish the different modes of changing the fluidity of solution: one is the variation of temperature at a constant chemical composition of the solution and the other is the variation of composition at a constant temperature $^{2,16)}$. In this study, we are going to discuss the effect of polymer concentrations and of the molecular masses of PEO and PVA on the fluidity of solution and diffusion coefficient of $\mathrm{Tl}(\mathrm{I})$ ion in the solution.

Figure 3 shows $\log D-\log \phi$ relationships for the aqueous solutions of PEO and PVA at con- stant temperature. When the polymer concentration is varied, linear correlations can be observed as shown by the solid lines, indicating that an equation similar to modified Walden's rule is satisfied:

$$
\begin{aligned}
& D(c) \phi(c)^{-q}=\text { constant } \\
& \quad \text { or } \ln \left(D / D_{0}\right)=q \ln \left(\phi / \phi_{0}\right)
\end{aligned}
$$

where $c$ is the polymer concentration, and $D_{\mathrm{o}}$ and $\phi_{\mathrm{o}}$ are the values of $D$ and $\phi$ for aqueous solutions containing no polymers.

Parameter $q$ in the isothermal concentration variation for a given polymer can be written by the equation,

$$
q=\frac{(\partial \ln D / \partial c)_{T}}{(\partial \ln \phi / \partial c)_{T}}
$$

which shows that $q$ is a parameter given by a ${ }_{2:-}^{*}$ ratio of the concentration dependence of $D$ and that of $\phi$ for a given polymer at constant tem-

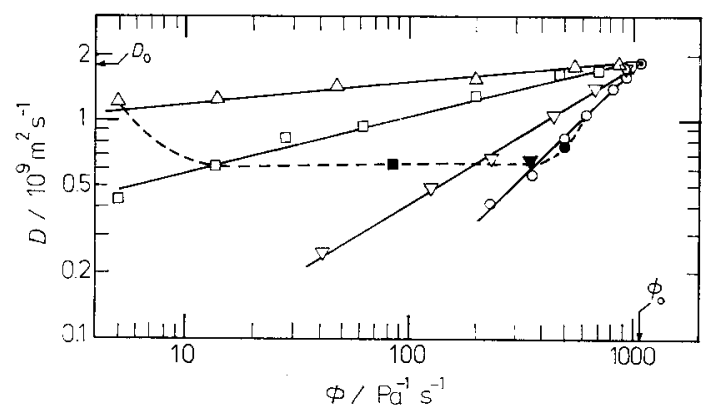

Fig. 3 Relationship between $\log D$ and $\log \phi$ with concentration variation of polymers at $25^{\circ} \mathrm{C}$ (broken line represents the iso-concentration curve for $f_{m}=$ 0.167 )

$$
\begin{aligned}
& \bigcirc: \text { PEG 200, : PEG 600, } \nabla: \text { PEG } 1540 \\
& \nabla: \text { PEG 4000, }: \text { PEG 6000, } \square: \text { PEG } 20000 \\
& \triangle: \text { PVA } 500
\end{aligned}
$$


perature.

Parameter $q$ was found to be dependent on the molecular mass of PEO and PVA as shown in Fig. 4. In the case of PEG 200, 600, and 1540, $q$-values are approximately unity, in other words, the classical Walden rule can be satisfied in these systems. This result suggests that the viscous flow and ionic diffusion in these solutions are affected by the addition of the polymers in a similar manner.

Figure 4 shows that the $q$-value decreases suddenly with increasing molecular masses of PEO. Lower values of $q$ mean that the effect of polymer on the viscous flow of solution is much greater than that on the movement of small ions in the solution. In solutions containing PEO 3 and PEO 18, the linear correlation between $\log D$ and $\log \phi$ did not appear; this is probably due to the fact that the viscous flow of these polymer solutions is non-Newtonian. Approximate $q$-values for these systems were estimated in the low concentration region and were shown with brackets in Fig. 4.

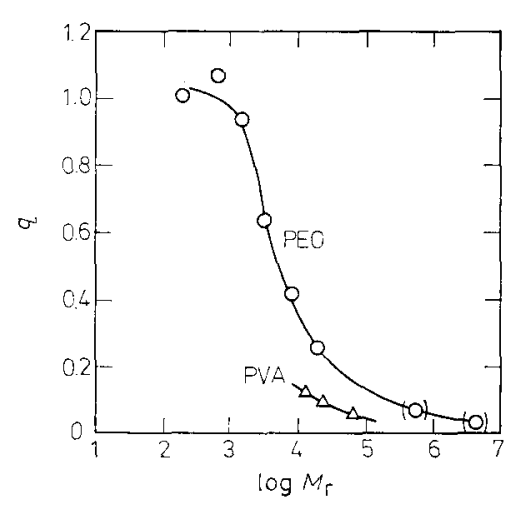

Fig. 4 Relationship between average relative molecular mass, $M_{\mathrm{r}}$, and $q$-value for $\mathrm{PEO}$ and PVA aqueous solutions

The broken line in Fig. 3 connects the points for solutions containing the polymers of different molecular masses but at the same mass fraction of the polymer $\left(f_{m}=0.167\right)$; the line represents the effect of molecular mass of polymer on the fluidity and ionic difusion. Although no simple correlation can be observed, the diffusion coefficient of $\mathrm{Tl}(\mathrm{I})$ is nearly constant when the molecular mass of $\mathrm{PEO}$ is in a certain range $M_{\mathrm{r}}=1540 \sim 20000$. The constancy of $D$ inde- pendent of $M_{\mathrm{r}}$ seems to support the obstruction theory to explain the effect of adding polymers on diffusion coefficients. According to this theory, the diffusion coefficient in a solution containg insulating spheres at volume fraction $f_{v}$ may be given by the equation ${ }^{2}$,

$$
D / D_{\mathrm{o}}=1-1.5 f_{v}
$$

If we assume that in the PEO solutions volume fraction $f_{v}$ may be replaced by mass fraction $f_{m}$, eq. (7) gives $D=1.4 \times 10^{-9} \mathrm{~m}^{2} \mathrm{~s}^{-1}$ for $\mathrm{Tl}$ (I) in PEO solutions at $f_{m}=0.167$, whereas the corresponding $D$-values experimentally obtained in solutions of PEO $\left(M_{\mathrm{r}}=1540 \sim 20000\right)$ were about $0.6 \times 10^{-9} \mathrm{~m}^{2} \mathrm{~s}^{-1}$. This result suggests that the effect of $\mathrm{PEO}$ on the diffusion of small ionic species in aqueous solutions cannot be explained in terms of the simple obstruction theory.

\subsection{Conclusion.}

The fluidity of aqueous polymer solutions and the diffusion of small ions in the solution are affected by the following factors; (1) structure of polymer chains in the solution, (2) structure change of water due to the influence of polymerwater interactions, and (3) the polymer-ion interactions. Since no significant change in the half-wave potential of $\mathrm{Tl}(\mathrm{I})$ reduction was observed with the composition variation of solutions in our experiment, the interaction between $\mathrm{Tl}(\mathrm{I})$ ion and the polymers can be considered to be negligibly small. A preliminary study using $60 \mathrm{MHz}$ proton magnetic resonance (PMR) showed that the P.YR line-width for water in the PEO and PVA. solutions was not broadened significantly, only $1.1 \sim 1.7$ times broader than that for pure water, which suggests that the structure of water is not very much influenced by the presence of PEO and PVA ${ }^{17,18}$. Concerning the structure of $\mathrm{PEO}$ and PVA in aqueous solutions, the long-chain polymer molecules are considered to form a loosely coupled network, which strongly decteases the macroscopic fluidity of the solutions but gives very little effect on the mobility of small ions which can pass through the loose network of polymers. It can be concluded that parameter, $q$, in the modified Walden rule (eq. (5)) provides useful information when the relationship between the viscous flow and the mobility of ions is discussed in solutions containing polymer molecules. 
Acknowledgment: We thank Mr. M. Hayashi of Seitetsukagaku Co. Ltd. who kindly provided us with the samples of Polyethylene Oxides and useful information about the samples. We also thank Dr. H. Honma and Dr. J. Uzawa of this Institute for the determination of average relative molecular masses of polymers and the PMR measurernent, respectively.

\section{References:}

1) J.O'M. Bockris and A.K.N. Reddy, "Modern Electrochemistry", Vol. 1 (1970), Chap. 4.4, Plenum Press, New York.

2) R.A. Robinson and R.H. Stokes, "Electrolyte Solutions", pp. 284-335 (1965), Butterworths, London.

3) P. Walden, H. Vlich and B. Busch, Z. Physik. Chem. A 123, 429 (1926); P. Walden and E.J. Birr, ibid. A 153, 429 (1926).

4) P.H. Hermans, "Colloid Science", Vol. II (1949), Chap. XII, ed. by H.R. Kruyt, Elsevier, Amsterdam.

5) R.H. Stokes and R. Mills, "Viscosity of Electrolytes and Related Properties", (The Intern. Encyclopedia of Physical Chem. and Chemical Phys. 3/16), pp. 52-61 (1965), Pergamon Press, Oxford.

6) R.L. Kay, "Water, A Comprehensive Treatise", Vol. 3 (1973), Chap. 4, ed. by F. Franks, Plenum Press, New York.

7) S. Hoshino and K. Sato, Kagaku Kogaku 31, 961 (1967); S. Hoshino, ibid. 34, 393 (1970); S. Hoshino, T. Oike and H. Yakura, ibid. 36, 433 (1972).

8) M. Suzuki and S. Sawada, Rev. Polarog. (Kyoto) 17, 69 (1971); M. Suzuki, S. Sawada and K. Yasuda, ibid. 18, 1 (1977).
9) M. Suzuki and T. Shimizu, Denki Kagaku 45, 361 (1977); T. Shimizu and M. Suzuki, ibid. 47, 17 (1977).

10) A. Laird Slade, A.E. Cremers and H.C. Thoman, J. Phys. Chem. 70, 2840 (1966).

11) R.H. Stokes and I.A. Weeks, Aust. J. Chem. 17, 304 (1964).

12) T. Isono, Rikagaku Kenky'tesho Hokoku 56, 55 (1980).

13) I.M. Kolthoff and J.J. Lingane, "Polarography", 2 nd ed. Vol. 1 (1952), Chap. 2, Interscience, New York.

14) J. Kuta and I. Smoler, "Progress in Polarography", Vol. 1 (1962), Chap. III, pp. 43-63, ed. by P. Zuman and I.M. Kolthoff, Interscience Pub., New York.

15) H. Ikeuchi, Y. Fujita, K. Iwai and G.P. Satô, Bull. Chem. Soc. Japan 49, 1883 (1976); H. Ikeuchi, K. Iwai, M. Kaneko, M. Maya and G.P. Satô, ibid. 52, 1863 (1979).

16) T. Isono, K. Takahashi and R. Tamamushi, Bull. Chem. Soc. Japan 54, 2183 (1981).

17) D.E. Woessner, B.S. Snowden, Jr. and Y.C. Chiu, $J$. Colloid Interface Sci. 34, 283 (1970); D.E. Woessner and B.S. Snowden, Jr., ibid. 34, 290 (1970).

18) M. Aizawa, J. Mizuguchi, S. Suzuki, S. Hayashi, T. Suzuki, N. Mitomo and H. Toyama, Bull Chem. Soc. Japan 45, 3031 (1972); M. Aizawa, S. Suzuki, T. Suzuki and H. Toyama, ibid. 46, 116 (1973).

(Received Dec. 22, 1980; Accepted Feb. 17, 1981)

\section{第 6 回 CA SEARCH オンラインによる化合物検索法講習会} 化学情報協会主催，電気化学協会ほ加協䝨

\author{
とき9月 25 日 (金) 10 時 \\ ところ 学会センタービル (東京都文京区弥生 2-4-16) \\ Chemical Abstracts のデータドースとCAS 化学物質登録 \\ システム/CA SEARCHによる化合物検索法と CAS 登録 \\ 番号の使い方 \\ (0)定 員 20 名
}

（）参加費 会員 9,000 円 会員外 15,000 円（テキスト含）

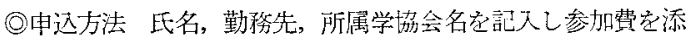
え⑪3 東京都文京区弥生 2-4-16 学会センタービル 化学 情報協会 (官 03-816-3462, 第一歓籍銀行根津支店普通預金 1225340）宛申し达导こと. 